\title{
Systemic lupus erythematosus: an occasional misdiagnosis
}

\author{
D A Collins, B E Bourke
}

\section{Case report}

A 54 year old West Indian woman with hypertension and diet controlled diabetes mellitus was admitted with a six week history of general malaise, fever, mouth ulceration, myalgia, arthralgia, and arthritis; previously she had been well. On examination she was noted to be feverish $\left(38^{\circ} \mathrm{C}\right)$ with nail bed infarction, splinter haemorrhages, and mouth ulceration, but no rash or lymphadenopathy. There was generalised muscle and joint tenderness, with synovitis of the knees and ankles. Investigations revealed a normal haemoglobin concentration and platelet count, lymphopenia $\left(1000 / \mathrm{mm}^{3}\right.$; normal value (NV) $>1500 / \mathrm{mm}^{3}$ ), erythrocyte sedimentation rate (ESR) $59 \mathrm{~mm} / 1 \mathrm{st} \mathrm{h}$, and $\mathrm{C}$ reactive protein (CRP) $460 \mathrm{mg} / \mathrm{l}(\mathrm{NV}<80 \mathrm{mg} / \mathrm{l})$; creatine kinase, renal and liver function tests, electrocardiogram, and chest radiograph were normal. Echocardiogram revealed a moderate pericardial effusion, but no evidence of endocarditis, and screening for infection was negative.

A provisional diagnosis of a connective tissue disease was made and, whilst serological tests were pending, the patient was discharged from hospital with non-steroidal anti-inflammatory medication. However she was readmitted with worsening joint pains, pleurisy, and a widespread urticarial rash. Further investigations revealed her to be antinuclear antibody (ANA) positive (homogeneous pattern, titre not stated) and anticardiolipin antibody positive, but anti-DNA antibody negative. Complement and immunoglobulin concentrations were increased; rheumatoid factor, hepatitis serology, and Coomb's test were negative. A biopsy specimen from involved, non-light-exposed skin showed non-specific inflammatory changes with no lupus band on immunofluorescence. A diagnosis of systemic lupus erythematosus (SLE) was made, and her treatment drug was changed to prednisolone $20 \mathrm{mg}$ daily.

The patient's condition rapidly improved and she was able to return to work; her ANA became negative and the steroid dosage was gradually reduced to a maintenance level of $5 \mathrm{mg}$ daily. However, she continued to complain of general malaise and her ESR remained persistently $>50 \mathrm{~mm} / 1 \mathrm{st} \mathrm{h}$.

Twenty months after first presentation there was a marked deterioration in the patient's liver function (serum alanine aminotransferase 72 IU/l (normal range (NR) 5-40 IU/1), alkaline phosphatase 917 IU/1 (NR 30-100 IU/1), and $\gamma$-glutamyltransferase $836 \mathrm{IU} / \mathrm{NR}$ 0-30 IU/ 1)), and mild hypercalcaemia (corrected calcium $2.65 \mathrm{mmol} / \mathrm{l}$ (NR $2 \cdot 15-2.55 \mathrm{mmol} / \mathrm{l})$ ). Her ANA remained negative. A liver biopsy specimen revealed multiple non-caseating granulomata (figure) and her diagnosis was changed to sarcoidosis. Angiotensin converting enzyme concentration was subsequently found to be $284 \mathrm{IU} / \mathrm{l}$ (NV <105 IU/); repeat chest radiography showed no evidence of lung or hilar disease. Her steroids were increased, azathioprine was added to her treatment, and currently she remains well.

\section{Discussion}

SLE and sarcoidosis share many clinical and immunological features, including hyperglobulinaemia, decreased lymphoid responsiveness, and increased circulating immune complexes (table). Positive ANA is reported in association with sarcoidosis in up to $33 \%$ of patients during the acute phase, ${ }^{1}$ decreasing to the same frequency as in controls if the disease becomes inactive. ${ }^{2}$ Antibodies to double stranded DNA have not been reported.

Arthritis, bilateral hilar lymphadenopathy, and erythema nodosum (Löfgren's syndrome) is perhaps the most common presentation of sarcoidosis seen by the rheumatologist, but fevers, arthritis, mouth ulceration, and pleuropericarditis have all been described, both in early and in active chronic sarcoidosis, together with non-specific rashes and serological evidence of immune system activation.

Neither erythema nodosum nor hilar lymphadenopathy was present in the patient described, and with her clinical presentation and immunological abnormalities she fulfilled five of the 11 ARA classification criteria for SLE. ${ }^{3}$ CRP is not reliably decreased in SLE and the increased CRP concentration was felt to be compatible with her disease. The lupus band test is positive in only $50 \%$ of cases in uninvolved non-light-exposed skin, increasing to $90 \%$ in involved light exposed skin, and negative lupus band does not exclude the diagnosis. The disappearance of the ANA with persisting increase in ESR and deranged liver function were atypical, however, and led to review of the initial diagnosis.

Coexistent SLE with sarcoidosis is rare, with only five cases reported in the English literature, ${ }^{48}$ three of which ${ }^{4} 78$ showed features similar to those of the patient we describe, with early features giving a diagnosis of SLE, but 


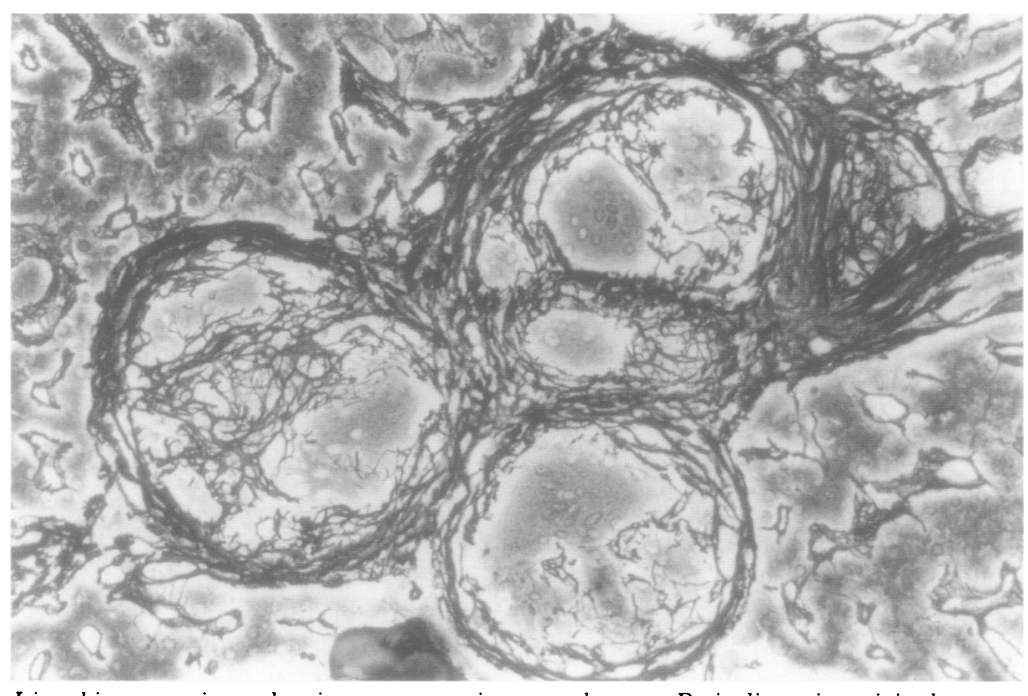

Liver biopsy specimen showing non-caseating granulomata. Reticulin stain; original magnification $\times 250$.

Similarities and differences in the investigation of systemic lupus erythematosus (SLE) and sarcoidosis

\begin{tabular}{|c|c|c|}
\hline & $S L E$ & Sarcoidosis \\
\hline \multicolumn{3}{|l|}{ Chest radiograph } \\
\hline Mediastinal lymphadenopathy & May be present & $\begin{array}{l}\text { Frequently present } \\
\text { (early disease) }\end{array}$ \\
\hline Interstitial lung disease & May be present & Common (late disease) \\
\hline ANA & + ve $95-100 \%$ & +ve $5-30 \%$ \\
\hline $\begin{array}{l}\text { Specific antibodies } \\
\text { (DNA, ENA) }\end{array}$ & Frequently present & Not reported \\
\hline Hypergiobulinaemia & Present & Present \\
\hline Hypocomplementaemia & Common & Not reported \\
\hline Immune complexes & Frequently present & $25-75 \%$ (with EN) \\
\hline Hypercalcaemia & Rare & Frequently present \\
\hline ACE & Normal & Frequently increased \\
\hline Kveim test & Negative & Positive \\
\hline
\end{tabular}

$\mathrm{ACE}=$ Angiotensin converting enzyme $; \mathrm{ANA}=$ antinuclear antibody $; \mathrm{EN}=$ erythema nodosum; $\mathrm{ENA}=$ extractable nuclear antigen .

development of sarcoidosis within 18 months. In addition, Soto-Aguilar et al reported a patient in whom sarcoid glomerulonephritis was initially mistaken for SLE. ${ }^{9}$ Non-caseating granulomas were reported in early studies of SLE, ${ }^{10} 11$ though whether this represents coexistent disease or mislabelling is not clear, and the frequency of the association of sarcoidosis and SLE remains unknown.

It would appear that the early immunological reactions of sarcoidosis may be mistaken for SLE, and this should be considered in the differential diagnosis and when the diagnosis is re-evaluated.

\section{The lesson}

- Sarcoidosis may mimic the clinical presentation of SLE, and fulfil the diagnostic criteria.

- Sarcoidosis should be considered in the differential diagnosis of SLE, both in the early stage and during long term follow up.

The authors are grateful to Dr Caroline Finlayson for providing the photomicrograph.

1 Veien N K, Hardt F, Bendixen G, et al. Immunological studies in sarcoidosis: a comparison of disease activity and various immunological parameters. Ann NY Acad Sci 1976; 278: $47-51$

2 Olenchock S A, Marx J J, Mull J C, et al. Immunology of clinically inactive sarcoidosis: serum factors. Am Allerg $1981 ; 47: 28-31$.

3 Tan E M, Cohen A S, Fries J F, et al. The 1982 revised criteria for the classification of systemic lupus erythematosus. Arthritis Rheum 1982; 25: 1271-7.

4 Harrison G N, Lipham M, Elguindi A S, Lobel D H. Acute sarcoidosis occurring during the course of systemic lupus erythematosus. South Med f 1979; 72: 1387-8.

5 Wiesenhutter C W, Sharma O P. Is sarcoidosis an autoimmune disease? Report of 4 cases and review of the literature. Semin Arthritis Rheum 1979; 9: 124-40.

6 Hunter T, Arnott J E, McCarthy D S. Features of systemic lupus erythematosus and sarcoidosis occurring together. Arthritis Rheum 1980; 23: 364-6.

7 Needleman S W, Silber R A, Von Brechy J H, Goeken J A Systemic lupus erythematosus complicated by disseminated sarcoidosis. Am 7 Clin Pathol 1982; 78: 105-7.

8 Hammond J M J, Bateman E D. Successful treatment of life-threatening steroid resistant pulmonary sarcoidosis with cyclosporin in a patient with systemic lupus erythematosus. Respir Med 1990;84: 77-80.

9 Soto-Aguilar M C, Boulware D W. Sarcoidosis presenting as antinuclear antibody positive glomerulonephritis. Am as antinuclear antibody positic
Rheum Dis 1988; 47: 337-9.

10 Teilum G. Miliary epithelioid-cell granulomas in lupus erythematosus disseminatus. Acta Pathol Microbiol Scand 1945; $22: 73-9$

11 Pollak A D. Some observations on the pathology of systemic lupus erythematosus. 7 Mount Sinai Hosp NY 1959; 26:
$224-40$. 